\title{
Music and Dance Thought of Empress Wu Zetian and Its Contribution to Dance in Tang Dynasty
}

\author{
Yang Song \\ Xi'an Conservatory of Music, Xi'an, Shaanxi, 710061, China
}

\begin{abstract}
Keywords: Empress Wu Zetian, Music and dance thought, Tang Dynasty, Dance, Development, Influence, Analysis.
\end{abstract}

\begin{abstract}
With a general survey of development system of ancient dance, the dance in Tang Dynasty was a peak of music and dance development in ancient times under the influence of music and dance thought in Tang Dynasty. This is because dance awareness in this period had owned independent performance art style. Especially in the period ruled by Empress Wu Zetian, the development of music and dance thought became more prominent. Thus, the dance in Tang Dynasty gained very outstanding development in terms of content, art form and action skills etc. On this basis, this paper takes music and dance thought in the period ruled by Empress Wu Zetian as the object of study, explains it in detail and analyzes the promotion function of development of music and dance thought on dance development in Tang Dynasty. Meanwhile, this paper demonstrates the unique advantages of dance art in Tang Dynasty in aesthetics and emotion.
\end{abstract}

\section{Introduction}

Relevant research scholars have published over 200 papers and more than 30 monographs about the researches on contributions and faults of Empress Wu Zetian. The cultural achievements involve the period ruled by Empress Wu Zetian. The researches on such fields as military, culture, talent employment, policies, economy and poem receive the most attention. However, the researches on music and dance thought of Empress Wu Zetian are not complete, and even have certain deficiencies. However, the ptomotion function of music and dance thought of Wu Zetian on development of dance in Tang Dynasty is a fact, and the function is very prominent. The most intensive manifestation is "Shiwan Palace Music and Dance" invested and created by Empress Wu Zetian. This proves the outstanding achievement of Empress Wu Zetian in music and dance. Thus, this paper analyzes music and dance thought in the period ruled by Empress Wu Zetian, its key influence and value in promoting and driving dance development in Tang Dynasty, in the hope of all parties pay attention and value it. To be more specific, the following key problems are involved.

\section{Analysis of background of forming music and dance thought of Empress Wu Zetian}

When numerous researchers study music and dance thought in the flourishing period of Tang Dynasty, they have found a key factor which drives the music to develop and boom is that, active advocacy and promotion of music and dance in the period ruled by Empress Wu Zetian. According to the records of relevant historical materials, we can easily find that as the sole female ruler in the history of China, Empress Wu Zetian (624-705) had served as "talented lady" since she entered the palace at the age of 14, which opened the "prelude" of researches on Empress Wu Zetian, music and dance. After Empress Wu Zetian entered the palace for 18 years, she ascended the throne at the age of 33 and ruled Tang Dynasty to develop for 50 years. Due to the particularity of Empress Wu Zetian among the rulers in the past dynasties, the researches on "contributions" and "faults" of Empress Wu Zetian receive special attention of researchers.

From the perspective of cultural history development, the period of Empress Wu Zetian is one of crucial periods and stages in culture and art system construction and development process in Tang Dynasty. In the period ruled by Empress Wu Zetian, due to special requirements for music prompting prosperity and sing the praises of Empress Wu Zetian, music and dance as well as the 
whole dance system got very outstanding development. Talented people were encouraged to study music and dance. Meanwhile, Empress Wu Zetian had outstanding historic contributions to enthusiasm and initiative in dance art development process.

\section{Basic manifestations of music and dance thought of Empress Wu Zetian}

The early research of Empress Wu Zetian on music activity mainly focused on the period when she served as a "talented lady". According to historical records, Empress Wu Zetian served as a "talented lady" for 14 years, from the age of 14 to the age of 27. She never gave up to pursue and study music activity. Historical data in New Book of Tang show that talented people have the skills to master the power, and they are quite eloquent. "Talent lady" here can be understood as follows: a special female official in the imperial harem. The main work of "talented ladies" is to manage all kinds of banquets and music in the imperial harem. Meanwhile, during selecting talented ladies”, they should not just be good at diction, but also should own multiple skills such as horse riding and archery. Du Fu wrote in the poem Ai Jiang Tou that, the talented lady takes bow and arrow, and rides a white horse. She shots at the cloud and shoots a bird. This poem describes Empress Wu Zetian when she served as the "talented lady". Empress Wu Zetian as the "talented lady" was mainly responsible for such affairs as horse riding and shooting. Besides, she needed to take charge of music management and activity in the imperial harem. The work in this period laid a foundation for Empress Wu Zetian to develop music and dance in later period.

Like Emperor Taizong of Tang, in the period ruled by Empress Wu Zetian, Empress Wu Zetian payd special attention to propriety and music culture construction. Relevant data verified the records in Old Book of Tang • Empress Wu Zetian that, in period ruled by Empress Wu Zetian, she often called in Zhou Simao, Wei Jingye, Fan Fubing and other bachelors of arts and asked them to write data and materials about propriety and music culture, including Shao Yang Zheng Fanm Qing Gong Ji Yao, Xiao Zi Lie Nv Zhuan and Wei Cheng Dian Xun etc. The above data and documents were finally collected in the private cabinet. In this process, a few articles came from self-writing, whole most of them were written on behalf of others. The most crucial one is monograph in temperament field - Yue Shu Yao $\mathrm{Lu}$ which received special attention. Meanwhile, it is also a key entry point in the process of studying music and dance thought of Empress Wu Zetian. Through verification of relevant practical experience and deep research of researchers, we can basically affirm that, Empress Wu Zetian is not the author of Yue Shu Yao Lu. It was written by others on behalf of Empress Wu Zetian. the most crucial role that Empress Wu Zetian played tends to "chief editor".

When Empress Wu Zetian created poems, some poems fully reflected her outstanding attainments in music and dance research field in terms of the form and content. Specifically speaking, the poems which were written by Empress Wu Zetian mainly include Chui Gong Ji 100 volumes, Jin Lun Ji 6 volumes and Cheng Gui 2 volumes. Besides, in the poem collection of Xiang Ming Tang Yue Zhang, the titles of poems (including "Li He”, “Tong He”, "Xian He”, "Jing He”, “Qi He”, "De He” and "Gui He"), reflect the proficiency of Empress Wu Zetian in temperament. Under such background, the most prominent manifestations of music and dance thought in the period of Empress Wu Zetian can be boiled down to three aspects: (1) relatively enlightened culture, education, rites and music policies were implemented in the period of Empress Wu Zetian, which laid a foundation for the development of music and dance art; (2) the talents who passed imperial examinations were valued, and a large number of literature and art talents were absorbed through advocating government by culture; (3) Empress Wu Zetian paid attention to carrying forward the music of national minorities and external music culture; (4) she focused on collection and organization of music documents and even writing music documents. The above measures laid a solid foundation for further developing dance in Tang Dynasty and had very outstanding contributions to integrated development of music and dance in the flourishing Tang Dynasty. 


\section{Contributions of music and dance thought of Empress Wu Zetian to dance in Tang Dynasty}

Large quantities of historical data investigations and researches verify that a key factor for booming development of dance art in the period of Empress Wu Zetian is that, comprehensive national strength was strong in that period; social thought was open; exchange and communication activities of multiple nations and foreign countries were frequent; both the dominance hierarchy and common people significantly improved their attention to dance activities. In this development period, appreciating rich and colorful dance performance had become a key element and basic need of social public. Meanwhile, processed court music and dance from the folk also get significant development. In the period of Empress Wu Zetian, the development and improvement of dance institutions were enhanced to facilitate better development of dance art. To be more specific, under the influence of music and dance thought of Empress Wu Zetian, dance in Tang Dynasty mainly reflects the following prominent features:

\section{More meaningful dance themes}

The main idea reflected in literary works is the meaning of dance theme, and it is the core element of works. Meanwhile, it is also an important content which decides reservation value and cultural connotation of a literary works. Under the music and dance thought of Empress Wu Zetian, the expression of theme meaning by dance aroused special attention in this period and even in follow-up period. This is reflected in the following two aspects: (1) the relationship between dance and politics is close. Popularly speaking, "military attack" and "government by culture" were combined. Praising and advocating the time of peace and prosperity were conducted from the perspective of culture, and most dances were court dances. For example, in the period ruled by Empress Wu Zetian, Chao Tian Ge was performed during ascending the throne and receiving the celebration of foreign envoys; Song Sheng Ping mixed with "lotus light dance" was performed during sacrificing to heaven and praying for good weather for the crops and good harvests". The above dances present the closer relationship with politics to different degrees. Dances served for politics; (2) dance and social life had close relationship. Simply speaking, the dance as the carrier was used to publicize the thought beneficial to social stability. For instance, the dance for two people Ta Yao Niang advocated correct concept of family ethic to social public so as to reach the purpose of family harmony and social harmony through depicting the protagonist who excessively drank, beat up his wife and finally was condemned by the audiences.

\section{More abundant and colorful dance forms}

The expression of culture and art depends on the form to a great extent. How to present culture and art in a more beautiful form? Art workers pay attention to this problem all the time. In the period ruled by Empress Wu Zetian, dancers focused on dance form richness and diversity in an unprecedented way. Thus, dance works in this period were favored by social public. In this period, rich and colorful dance forms were mainly reflected in the following aspects: (1) richness of dance forms: in the period ruled by Empress Wu Zetian, the popular dances not only included Ta Yao Niang of traditional drama form, but also included the dance of text structure form, such as Qing Tian Yue; (2) richness of performance scale: in the period ruled by Empress Wu Zetian, among all kinds of representative dance works, there were not just solo dances such as Mei Niang You Chun and Wang Fo Fei Tian Wu, but also dances for two people such as Ta Yao Niang. Besides, there were large-scale dances such as Song Sheng Ping, Tian Chang Jiu, Chun Jiang Hua Yue Ye and Chao Tian Ge. The scale was larger than before; (3) colorfulness of music accompaniment: in the period ruled by Empress Wu Zetian, among all kinds of dance works, there were dance works accompanied with music such as Sheng Ming Yue, but also dances works in which dancing and singing were performed at the same time such as Sheng Shi TianChang Jiu. It is easy to find that in the period ruled by Empress Wu Zetian, manifestation forms of dances in Tang Dynasty were rich and colorful. On the one hand, the connotation of dance art could be expressed well; on the other hand, new feeling and art edification were brought for audiences. This laid a more solid foundation for development of dance art in the late Tang Dynasty. 


\section{Conclusion}

Stable political situation, flourishing economic exchange and coexistence of diversified culture promoted development of music and dance in the period ruled by Empress Wu Zetian. In addition, music and dance thought of Empress Wu Zetian created a favorable environment foe dance art development in this period. In this period, Empress Wu Zetian not merely focused on development of music and dance culture of the nation, but also extensively absorbed development features of music and dance culture of foreign countries and other minority areas. Due to the influence of the above factors, dance further had meaning in the theme, and became more rich and colorful in the form. Hence, the dance in Tang Dynasty under music and dance thought was a peak in music and dance development in ancient times. This is because dance awareness in this period completely owned independent performance art style. The role of Empress Wu Zetian and her prominent contributions are the priority among priorities, so they deserve attention.

\section{References}

[1] Chen Wei, Music and dance worshipping Confucius and state will expression - study on the relationship between music and dance worshipping Confucius in Jianshui in the south of Yunnan and state system, The Religious Cultures in the World, 2011,(6):84-87.

[2] Li Rongyou, Interpretation of painting, music and dance art in Han Dynasty in view of folk culture - case study of Nanyang Tomb with Dtone Relief in Han Dynasty, Huang Zhong - Journal of Wuhan Conservatory Of Music, 2009,(4):138-147.

[3] Gao Jianxin, "Three dances accompanied with music” in the Western Regions in poetry of the Tang Dynasty - Hu Xuan Dance, Hu Teng Dance and Zhe Zhi Dance, Studies of Ethnic Literature, 2012,(6):128-137.

[4] Zhu Limin, Bai Yuemei, Great Tang: an open and booming dynasty in culture - cultural interpretation of music, dance and mural in Tang Dynasty, The Journal of Humanities, 2001,(2):122-125.

[5] Cai Lihong, music and dance culture exchange strategy of China with neighboring countries in the period of Ming and Qing Dynasty - case study of culture line of ocean and continent silk road, Journals of Fujian Normal University (Philosophy and Social Science Edition), 2011,(6):157-160,171.

[6] Wu Shaojing, Thought on innovative performance form of Nanyin music and dance - case study of Nanyin music and dance in Taiwan Han Xi Zai Ye Yan Tu, Journal of Zhejiang Vocational Academy of Art, 2012,10(4):55-59.

[7] Wu Geng, Liu Fengxue, Wish reconstruction of music and dance in Tang Dynasty to become springhead of music and dance innovations of China - interview record of famous dancer Dr. Liu Fengxue, Symphony - Journal of Xi'an Conservatory of Music, 2010,29(3):51-54.

[8] Wu Xiang, Precedent of music and dance education in ancient China - on music and dance education in Zhou Dynasty and its enlightenment on current dance education, Literature Life, 2011,(7):104-105,109.

[9] Yang Fang, Wang Qiang, Cultural relics of Uigurian dance under influence of music and dance in the Western Regions - case study of Qiuci music and dance, Bulletin of Sport Science \& Technology, 2010,18(1):123-124.

[10] Yang Minkang, Tao song singing of Beijing Tibetan Buddhism in Qing Dynasty and art monk system - on contributions of Sanshi Zhangjia Living Buddha to inheriting and communicating Buddhism music and dance in Mongolia and Tibet, Huangzhong - Journal of Wuhan Conservatory Of Music, 2011,(4):228-232. 